\title{
Comment on: H-Index Is an Ugly Truth; But What About Other Scientometric Criteria?
}

\author{
Hadi Esmaily ${ }^{1}$, Elmira Niknami ${ }^{2}$ and Ali Saffaei ${ }^{3,}{ }^{*}$ \\ ${ }^{1}$ Department of Clinical Pharmacy, School of Pharmacy, Shahid Beheshti University of Medical Sciences, Tehran, Iran \\ ${ }^{2}$ Student Research Committee, School of Pharmacy, Isfahan University of Medical Sciences, Isfahan, Iran \\ ${ }^{3}$ Student Research Committee, Department of Clinical Pharmacy, School of Pharmacy, Shahid Beheshti University of Medical Sciences, Tehran, Iran \\ "Corresponding author: Resident of Clinical Pharmacy, Student Research Committee, Department of Clinical Pharmacy, School of Pharmacy, Shahid Beheshti University of \\ Medical Sciences, Niayesh Junction, ValiAsr St., P. O. Box: 1991953381, Tehran, Iran. Tel: +98-9128251633, Fax: +98-2188873704, Email: alisaffaei.ss@gmail.com
}

Received 2019 June 09; Accepted 2019 June 13.

Keywords: H. Index, Scientometric, Ethics, Scientometric Criterion

\section{Dear Editor,}

It is my pleasure to find the opportunity to read the valuable article by Sabour published in the last issue of the journal (1). This article explains an important issue regarding H-index as a scientometric criterion. The author criticized the H-index and mentioned seven weak points for it. Hirsch introduced the H-index as a research output measure first (2). The H-index has specific advantages, representing the author's productivity with echo. It is not affected by extreme values in terms of articles without any citation or articles with a high number of citations. This index determines the most relevant articles according to the citation numbers (3). H-index, like any scientometric criteria, has some disadvantages, as well. Some of these disadvantages were correctly addressed in the above-mentioned article. However, some mentioned weaknesses are not directly related to $\mathrm{H}$-index and every scientometric criterion may suffer from these shortcomings. For example, the author stated that research managers have high $\mathrm{H}$-index values owing to their positions. It is obvious that not only $\mathrm{H}$-index, but also every scientometric criterion may be increased in these situations. The author mentioned the selling and purchasing of articles as another weakness. This is an inauspicious unethical phenomenon in the research world. This phenomenon can negatively affect not only the H-index, but also other scientometric criteria. Another mentioned weakness was a high H-index owing to selfcitation. It can be resolved by calculating it without selfcitations (3). The author also stated "corresponding authors contribute very little to the publication of the study, and in some cases, do not even read the articles published with their name" and claimed that this could increase $\mathrm{H}$ - index falsely. This unethical issue must be controlled with authorship contribution criteria, and every scientometric criterion may be influenced by such an unethical issue. In conclusion, the author addressed some weaknesses of $\mathrm{H}$ index, which not all of them are specific to $\mathrm{H}$. index, particularly those related to unethical issues in research. New scientometric criteria may also be influenced by them; therefore, appropriate strategies should be considered to cope with these problems.

\section{Footnotes}

Conflict of Interests: None. Funding/Support: None.

\section{References}

1. Sabour S. H. Index, an Ugly Truth. Shiraz E-Med J. 2019;20(5). e84554. doi: $10.5812 /$ semj.84554.

2. Hirsch JE. An index to quantify an individual's scientific research output. Proc Natl Acad Sci U S A. 2005;102(46):16569-72. doi: 10.1073/pnas.0507655102. [PubMed: 16275915]. [PubMed Central: PMC1283832].

3. Bartneck C, Kokkelmans S. Detecting h-index manipulation through self-citation analysis. Scientometrics. 2011;87(1):85-98. doi: 10.1007/s11192-010-0306-5. [PubMed: 21472020]. [PubMed Central: РМС3043246]. 